\title{
Charge balanced control of seizure like activity in a two dimensional cortical model
}

\author{
Prashanth Selvaraj ${ }^{1 *}$, Andrew Szeri $^{1,2}$ \\ From Twenty First Annual Computational Neuroscience Meeting: CNS*2012 \\ Decatur, GA, USA. 21-26 July 2012
}

The invasiveness of surgical procedures and the ineffectiveness of medication in remedying seizures in some epileptic patients have led to investigations into alternative methods such as feedback control. While the methods for applying control are varied, the underlying idea is to use electrical signals to disrupt irregular cortical activity. Experimentally, an adaptively applied radial electric field has been shown to control seizure like activity in a mammalian brain [1].

In previous work, a meso scale model consisting of stochastic partial differential equations was developed [2]. Seizure like activity has been simulated with this model, and successfully suppressed using charge balanced electrical control [3]. The magnitude of control was related to the signal sensed at the cortical surface. This work extends previous research to a two dimensional meso scale cortical model. Cortical waves in a two dimensional spatial domain present more complex dynamics than are seen in the one dimensional model, with a greater variety of instabilities of the basic (healthy) states. This presents greater challenges for successful control.

\section{Acknowledgements}

This work has been partly supported by a research grant from the National Science Foundation (NSF).

\section{Author details}

${ }^{1}$ Department of Mechanical Engineering, University of California, Berkeley, CA 94703, USA. ${ }^{2}$ Center for Neural Engineering and Prosthesis, UC Berkeley and UC San Francisco, USA.

Published: 16 July 2012

\footnotetext{
* Correspondence: pselvaraj@me.berkeley.edu

'Department of Mechanical Engineering, University of California, Berkeley, CA 94703, USA

Full list of author information is available at the end of the article
}

References

1. Richardson KA, Gluckman BJ, Weinstein SL: In vivo modulation of hippocampal epileptiform activity with radial electric fields. Epilepsia 2003, 44(6):768-777.

2. Liley DTJ, Cadusch PJ, Wright JJ: A continuum theory of electro-cortical activity. Neurocomputing 1999, 26-27:795-800.

3. Lopour BA, Szeri AJ: A model of feedback control for the chargebalanced suppression of epileptic seizures. J Comput Neurosci 2010, 28:375-387.

doi:10.1186/1471-2202-13-S1-P33

Cite this article as: Selvaraj and Szeri: Charge balanced control of seizure like activity in a two dimensional cortical model. BMC Neuroscience 2012 13(Suppl 1):P33.
Submit your next manuscript to BioMed Central and take full advantage of:

- Convenient online submission

- Thorough peer review

- No space constraints or color figure charges

- Immediate publication on acceptance

- Inclusion in PubMed, CAS, Scopus and Google Scholar

- Research which is freely available for redistribution

Submit your manuscript at www.biomedcentral.com/submit
() Biomed Central
C Biomed Central

(c) 2012 Selvaraj and Szeri; licensee BioMed Central Ltd. This is an Open Access article distributed under the terms of the Creative Commons Attribution License (http://creativecommons.org/licenses/by/2.0), which permits unrestricted use, distribution, and reproduction in any medium, provided the original work is properly cited. 